\title{
TiNb-esaslı $\beta$-Ti Alaşımlarının Kristal Yapı, Mikroyapı ve Dönüşüm Sıcaklıklarına Tantal Katkısının Etkileri
}

\author{
Ercan ERCAN $^{1 *}$, Fethi DAĞDELEN ${ }^{2}$ \\ ${ }^{I}$ Bitlis Eren Üniversitesi, Fen Edebiyat Fakültesi, Fizik Bölümü, Bitlis \\ ${ }^{2}$ Fırat Üniversitesi, Fen Fakültesi, Fizik Bölümü, Elazığ \\ (ORCID: 0000-0002-1583-6068) (ORCID: 0000-0001-9849-590X)
}

\begin{abstract}
$\ddot{O} \mathbf{z}$
$\beta$-tipi Ti-esaslı alaşımlar yüksek sıcaklıktaki dayanıklılığı ve biyo-uyumluluğu sayesinde uzay teknolojisi ve medikal alanlarda kullanımı yaygın olan materyallerdir. Nb ve Ta gibi düşük yoğunluklu, üstün korozyon direnci ve toksik olmayan özelliklere sahip elementler ile takviye edilmesi, $\beta$-tipi Ti-esaslı alaşımları daha da çekici hale getirmiştir. Hazırlanan $\operatorname{TiNb}_{(24,5-x)} \operatorname{Ta}_{(x=0,1,2,3,4)}$ (at. \%) alaşımlarının kristalografik özellikleri, mikroyapısı ve dönüşüm sıcaklıkları incelendi. DSC analizlerinden $5,5^{\circ} \mathrm{C}$ ile $41,1^{\circ} \mathrm{C}$ aralı̆̆ında sadece $\alpha \rightarrow \beta$ ters dönüşümü gözlenmiş̧tir. Oda sıcaklığında yapılan XRD analizleri ile DSC sonuçlarının uyumlu olduğu görülmüsstür. Baskın $\beta$ fazlarına karşın $\alpha$ fazlarının küçük miktarlar da olduğu tespit edilmiştir. $\beta$ fazının baskın olması $\mathrm{Ta}$ ve $\mathrm{Nb}$ elementlerinin fazını kararlı hale getirdiği göstermiştir. Optik mikroskop görüntülerinden, Ta ilavesi ile tane yapıları içerisindeki $\beta$ fazının ve bu fazın tane sınırlarının belirginleştiği görülmüştür. $\alpha$ fazının, SEM-EDX görüntülerinden alınan sonuçlara göre çökelti fazı olduğu görülmüştür. Ayrıca EDX sonuçları ile Ta element konsatrasyonunun tane sınıllarında arttığı bulunmuştur. Alaşımların değerlik elektron sayısı $\left(e_{v} / a\right)$ ve ortalama değerlik elektron konsantrasyonu oranları $\left(c_{v}\right)\left[\left(e_{v} / a<5, c_{v} 0,15\right)\right]$ ile oda sicaklığı altında dönüşüm sergilemesi, bu alaşımların düşük değerli alaşımlar olduğunu gösterir.
\end{abstract}

Anahtar kelimeler: $\beta$-tipi Ti alaşımlar, kristal yapı, mikroyapı, ters dönüşümlü martensit.

\section{The Effects of Tantalum Additive on the Crystal Structure, Microstructure and Transformation Temperatures of TiNb-based $\beta$-Ti Alloys}

\begin{abstract}
$\beta$-type Ti-based alloys are materials which widely used in the aerospace technology and medical fields because it has a sufficient biocompatibility and high temperature resistance. Reinforcement with low-density, high corrosion resistance and non-toxic elements, such as $\mathrm{Nb}$ and Ta alloying with $\beta$-type of Ti-based alloys even more attractive. The crystallographic properties, microstructure and transformation temperatures of $\mathrm{TiNb}(24,5-\mathrm{x}) \mathrm{Ta}(\mathrm{x}=$ $0,1,2,3,4)$ (at.\%) alloys were investigated. The DSC analysis showed only $\alpha \rightarrow \beta$ reverse transformation for the temperature range of $5,5^{\circ} \mathrm{C}$ to $41,1^{\circ} \mathrm{C}$. DSC results were found to be compatible with X-ray analysis taken at room temperature. It was found that $\alpha$ phases were in small amounts despite dominant $\beta$ phases. The dominance of the $\beta$ phase has shown that the Ta and $\mathrm{Nb}$ elements are good stabilizer. It was observed from optical microscope images that the phase within the grain structures and the grain boundaries of this phase became clear with the addition of Ta. According to the results obtained from SEM-EDX images, the $\alpha$ phase was found to be the precipitate phase. Additionally, the EDX results showed that Ta elements concentration increased in the grain boundaries. The number of valance electrons $\left(e_{v} / a\right)$ and average concentration of valance electron $\left(c_{v}\right)$ values $\left(e_{v} / a<5, c_{v} \sim 0,15\right)$ and transformation below room temperature indicated that these alloys are low value alloys.
\end{abstract}

Keywords: $\beta$-type Ti, crystal structure, microstructure, reverse martensite.

\footnotetext{
*Sorumlu yazar: eercan@beu.edu.tr

Geliş Tarihi: 30.07.2020, Kabul Tarih: 03.10.2020
} 


\section{Giriş}

Son zamanlarda $\beta$-tipi Ti-esaslı alaşımlar, üstün korozyon direnci, yüksek mukavemet, yüksek biyouyumluluk ve yüksek sıcaklıkta kullanılabilme özelliklerinin yanı sıra düşük yoğunluklu olması sayesinde popüler hale gelmiştir [1-6]. $\beta$-tipi Ti alaşımlarının bahsedilen özelliklerinin yanında şekil hafiza etkisi ve süper-elastik malzemeler olması bu alaşım grubunun havacılık ve biyomedikal alanda sıklıkla kullanılmasını sağlamıştır $[2,4,7,8]$. $\beta$-tipi Ti-esaslı alaşımlarda şekil hafıza ve süper-elastiklik etkisini sağlayan, $\beta$ (düzensiz bcc), $\alpha^{\prime \prime}$ (altıgen martensit) ve $\alpha$ (ortorombik martensit) fazların varlığ1 önemlidir [2, 9]. Özellikle yarı-kararlı $\beta$ (düzensiz bcc) fazının ani soğutma, yaşlandırma ve deformasyon ile şekil hafiza özelliklerinin değiştiği bilinmektedir [10, 11]. Bu şekil hafiza davranışının alaşımın bileşimine bağlı olarak $\beta \leftrightarrow \alpha^{\prime \prime}$ veya $\beta \leftrightarrow \alpha$ martensitik dönüşümler sergilediği belirlenmiştir $[10,12]$. Bunun yanı sıra, süper-elastikliği içeren $\beta \leftrightarrow \alpha^{\prime \prime}$ veya $\beta \leftrightarrow \alpha$ faz dönüşümlerinin, $\beta$ stabilizatör (fazın dengelenmesi) element grupları olarak adlandırılan elementlerin takviyesi ile şekil hafıza özelliklerinin arttırılması da mümkündür. Bahsedilen $\beta$ stabilizatörlerin üç gruba ayrıldığ1 bilinmektedir. Bunlar [8, 11, 13, 14];

1. $\beta$-Ti'ye izomorf olan ve $\alpha$-fazında sınırlı çözünürlüğe sahip katı çözeltiler oluşturan elementler: $\mathrm{Ta}, \mathrm{Nb}, \mathrm{V}$ ve Mo,

2. $\beta$-Ti'ye izomorf olan ve $\alpha$ ve $\beta$-Ti'de sürekli çözünürlüğe sahip katı çözeltiler oluşturan elementler: $\mathrm{Zr}$ ve $\mathrm{Hf}$

3. $\alpha$ ve $\beta$-Ti'de sınırlı çözünürlüğe sahip katı çözeltiler oluşturan ve metaller arası bileşikler oluşturan elementler: $\mathrm{Mn}, \mathrm{Cr}, \mathrm{Fe}, \mathrm{Cu}, \mathrm{Ni}, \mathrm{Si}$, ve $\mathrm{Co}$

olarak sıralanmaktadır. Ayrıca yüksek sıcaklıkta altıgen kristal yapıya sahip Titanyumun stabilize edici elementlerin ilave edilmesiyle ortam koşullarında (oda sıcaklığı) yarı-kararlı faz yapısını da koruduğu bilinmektedir. Bu element grupları içerisinde $\mathrm{Ta}$ ve $\mathrm{Nb} \beta$-fazını en güçlü şekilde kararlı hale getirici olması bakımından önemlidir ve Ti-esaslı şekil hafizalı alaşımlara ilave edilmesi son yıllarda araştırmacıların dikkatini çekmiştir. Ta ve $\mathrm{Nb}$ ile oluşturulan TiNb ve TiNb-Ta alaşımların ani soğutma ile martensit fazdaki $\alpha^{\prime \prime}$ - fazının oluşumuna ve $\beta$-fazının oda sıcaklığında stabilize olmasını sağlamak martensit fazlar için önemlidir. TiNb alaşımlarına Sn, Al, O, N, Mo, Pt, Pd, Ta, Zr, gibi birçok element, farklı konsantrasyonlarda katkılanarak oluşturulan yeni alaşım gruplarının süper-elastik özellikleri birçok araştırmacılar tarafından incelenmiştir [15-23]. Ancak TiNb alaşımına bazı konsantrasyonlarda Ta elementinin ilave edilmesiyle oluşturulan alaşımların martensit faz özelliklerinin incelenmesinin hala eksik olduğu bilinmektedir. Yapılan bazı çalışmalarda artan $\mathrm{Nb}$ ve Ta element ilavesiyle dönüşüm sıcaklıklarının azaldığı görülmüştür. Ancak literatürde azalan Nb oranın da artan Ta ilavesi ile dönüşüm sıcaklıklarının nasıl değiştiği hakkında pek bilgi olmadığı görülmüştür.

$\mathrm{Bu}$ çalışmada TiNb alaşımlarına, toksik özelliği zayıf olan ve $\beta$ fazını kararı hale getiren Ta element katkısı ile farklı oranlarda yeni TiNb-Ta alaşımları üretip, atom başına değerlik elektronları $\left(e_{v} / a\right)$, ve değerlik elektronlarının ortalama konsantrasyon oranları $\left(c_{v}\right)$ hesaplanıp karşılaştırılması, değişen $\mathrm{Nb}$ ve Ta miktarı sonucundan alaşımlardaki kristal yapı, dönüşüm sıcaklığı ve mikroyapı değişimlerinin incelenmesi hedeflenmiştir.

\section{Materyal ve Metot}

Bu çalışmada, üretilmiş olan TiNb ve TiNb-Ta alaşımlarının Tablo 1'de verilen atom başına değerlik elektronları $\left(e_{v} / a\right)$, değerlik elektronlarının ortalama konsantrasyon oranları $\left(c_{v}\right)$ ve atomik oranları hesaplandi. \% 99,9 Ti, \% 99,9 $\mathrm{Nb}$ ve \% 99,9 saflıkta Ta (Merk marka - 325 merch) elementleri karıştırılarak toz numuneler elde edildi. Toz halindeki elementler homojen olarak karıştııılmasının ardından, yaklaşık $15 \mathrm{MPa}$ basınç altında ve $13 \mathrm{~mm}$ çapında peletler haline getirildi. Peletler, argon atmosferi altında Ark-ergitme yöntemi ile en az 5 kez yeniden eritilerek 20 gramlık numuneler üretildi. Bütün numuneleri homojenleştirilmek için kül firını ortamına argon gazı verilerek $850{ }^{\circ} \mathrm{C}$ de 24 saat süreyle bekletilip tuzlu - buzlu suda soğutuldu.

$\mathrm{X}$-1şını, optik mikroskop, SEM (Scanning Elektron Miroscope) ve DSC (Differantial Scanning Calorimeter) analizleri için Dremel 4200 elektrikli kesici yardımıyla belirli boyutlarda parçalar kesildi ve kesilen parçalardan elde edilen DSC numuneleri $850^{\circ} \mathrm{C}$ de 30 dakika süreyle tekrardan isttılıp tuzlubuzlu suda soğutuldu. Bu işlem dönüşüm sıcaklıkları belirlenecek numunelerdeki kesmeden kaynaklı zorların ortadan kaldırılması için yapıldı. Alaşımların X-ışını analizleri Bruker Discover D8 X-ray 
difraction (XRD) cihazı $\left(\mathrm{CuK}_{\alpha} \lambda=1,5418\right)$ kullanılarak $30-80^{\circ}$ arasında $2 \%$ dak. sabit tarama hizı ile oda sıcaklığında yapıldı. Optik mikroskop ölçümleri alınacak olan alaşımlar soğuk bakalite alınıp, METKON FORCIPOL-2 Zımparalama ve Parlatma Cihazında sirasiyla 240, 400, 600, 800, 1000, 1200 ve 2000 mesh zımpara kâğıtları kullanılarak zımparalandı. Çuha ve elmas pasta kullanılarak yüzeyleri parlatılan numuneler, $\mathrm{HNO}_{3}(5 \%)+\mathrm{HF}(10 \%)+\mathrm{H}_{2} \mathrm{O}(85 \%)$ oranlarında hazırlanan dağlayıcı yardımıyla 10 saniye süreyle dağlandı. Saf su ve alkol ile yüzeyleri temizlenip kurutulan numuneler NIKON MA100 Ters Metal Mikroskobu cihazı ile metalografik gözlemleri yapıldı. Ardından Jeol JSM 7001F SEM-EDX cihazı kullanılarak yüzey analizleri yapıldı. Son olarak dönüşüm sıcaklıklarını belirlemek için Perkin Elmer Sapphire marka DSC cihazı ile $10{ }^{\circ} \mathrm{C} /$ dak. 1 sıtma $\leftrightarrow$ soğutma hızıyla azot gazı atmosferinde 1sı akısı ölçümleri yapıldı.

Tablo 1. Hazırlanan numunelerin atomikçe (\% at), ağırlıç̧a (\% wt), atom başına değerlik elektronları ve değerlik elektronlarının ortalama konsantrasyon oranları

\begin{tabular}{|c|c|c|c|c|c|c|c|c|}
\hline & \multicolumn{3}{|c|}{$\begin{array}{c}\text { Kü̈llece } \\
\text { (\% ağırlıkça) } \\
\end{array}$} & \multicolumn{3}{|c|}{$\begin{array}{c}\text { Atomikçe } \\
(\% \text { atomikçe })\end{array}$} & \multirow{2}{*}{$\frac{e_{v}}{a}($ elektron/atom $)$} & \multirow{2}{*}{$c_{v}$} \\
\hline & $\mathbf{T i}$ & Nb & $\mathbf{T a}$ & $\mathbf{T i}$ & $\mathbf{N b}$ & $\mathbf{T a}$ & & \\
\hline E0 & 61,356 & 38,644 & - & 75,5 & 24,5 & - & 4,245 & 0,159 \\
\hline E1 & 60,452 & 36,521 & 3,027 & 75,5 & 23,5 & 1,0 & 4,225 & 0,156 \\
\hline E2 & 59,575 & 34,459 & 5,966 & 75,5 & 22,5 & 2,0 & 4,205 & 0,154 \\
\hline E3 & 58,723 & 32,456 & 8,821 & 75,5 & 21,5 & 3,0 & 4,185 & 0,151 \\
\hline E4 & 57,894 & 30,511 & 11,595 & 75,5 & 20,5 & 4,0 & 4,165 & 0,149 \\
\hline
\end{tabular}

\section{Bulgular ve Tartışma}

Şekil 1'de $\operatorname{TiNb}_{(24,5-x)} \operatorname{Ta}_{(x=0,1,2,3,4)}(\%$ at) oranlarında hazırlanan E0, E1, E2, E3 ve E4 numunelerinin oda sıcaklığında alınan X-1şını analizleri verildi. X-ışını difraktogramlarından elde edilen pikler incelendiğinde $\beta \leftrightarrow \alpha$ martensitik dönüşümü esnasında, kısmı dönüşüme bağlı olarak $\beta$ fazının piklerinin belirgin olduğu görülmüştür. Ayrıca $\beta$ fazının yanı sıra küçük miktarlarda $\alpha$ fazının varlığı mevcuttur. Artan Ta element ilavesi ile E1, E2, E3 ve E4 alaşımlarında görülen mevcut fazların pik şiddetlerinde azalmalar meydana gelmiştir. Pik şiddetlerindeki bu azalışın, yarı-kararlı $\beta$ martensit fazından kaynakladığı önceki çalışmalarda rapor edilmiştir $[4,7,9,24]$. TiNb ve TiNb-Ta alaşımlarındaki martensit dönüşümü sergileyen $\alpha^{\prime \prime}$ ve $\alpha$ faz piklerinin XRD analizlerinde düşük şiddetlerde görülmesi, martensit dönüşümün oda sıcaklığının altında meydana gelmesinden kaynaklanmaktadır. Ayrıca, TiNbesaslı alaşımlarda eklenen üçüncü element (Ta) ile $\beta$ martensit fazının $\alpha$ martensit fazına göre daha baskın olmasıyla $\beta$ martensit fazını dengelendiği de düşünülmektedir. $\beta$ martensit fazının baskın bir şekilde görülmesi, ilave edilen Ta elementinin iyi bir $\beta$ stabilizatör olduğu anlamına da gelmektedir. Austenit dönüşümün oda sıcaklığına yakın değerlerde meydana gelmesi, bu dönüşüm ile ilgili olan $\beta$ fazının X-ışını analizinde baskın olduğunun bir başka kanıtıdır. Ancak Dubinskiy ve arkadaşlarının TiNb-Ta alaşımları için 100 ile $-150{ }^{\circ} \mathrm{C}$ sıcaklık aralığında yapmış oldukları XRD analizlerinde, TiNbTa alaşımlarında aslında $\beta \leftrightarrow \alpha^{\prime \prime}$ dönüşümünün varlığının olduğu belirlenmiştir [10]. 


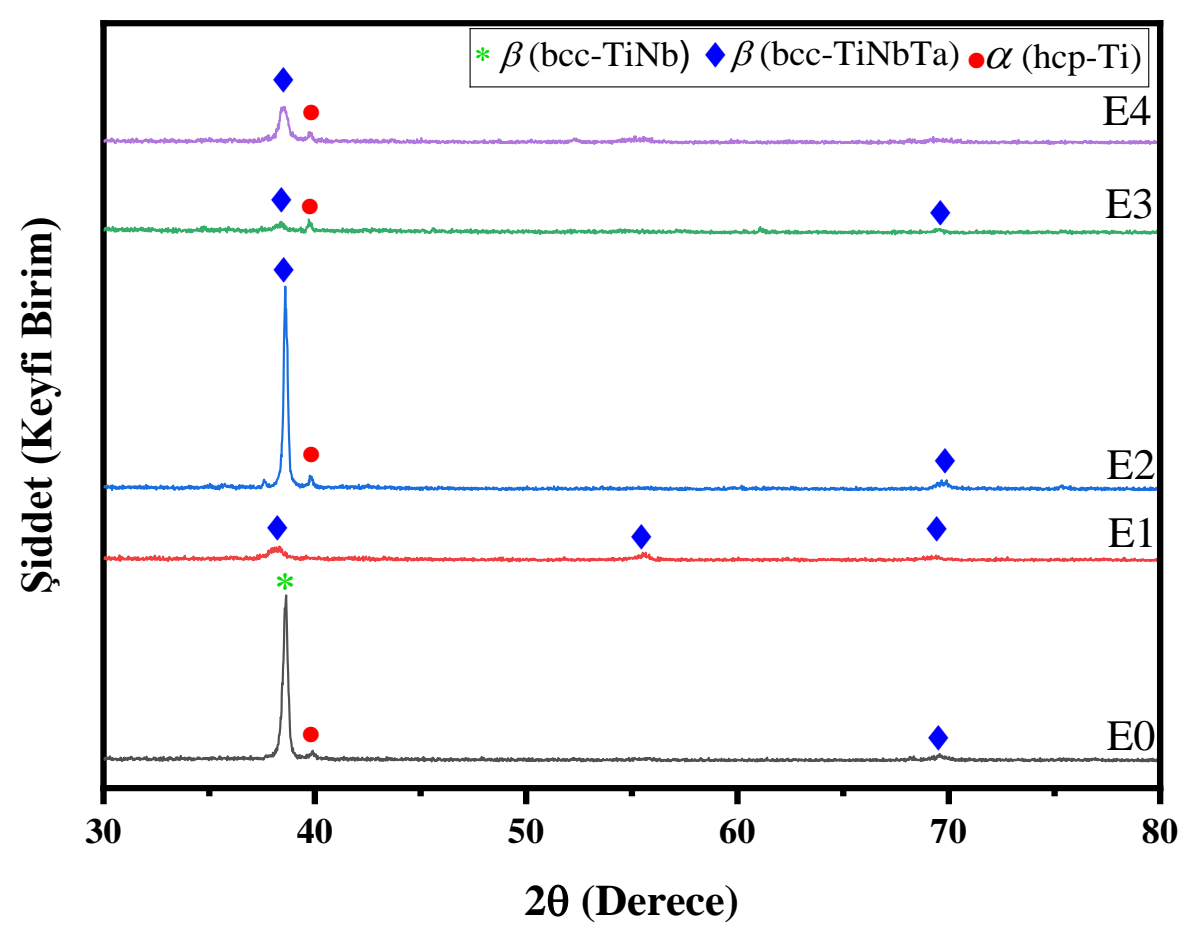

Şekil 1. Alaşımların oda sıcaklığında alınan X-1şınları difraktogramları

TiNb ve TiNb-Ta alaşımlarının Şekil 2 (a-e)'de incelenen optik mikroskop görüntüleri ile XRD analizleri ile elde edilen fazların uyumlu olduğu söylenebilir. $850^{\circ} \mathrm{C}$ 'de homojenleştirme işlemi için 1sıtılıp ardından tuzlu-buzlu su ile ani soğutulan alaşımlarda oluşan $\beta$ fazının tipik mikroyapısı tüm alaşımlardaki tane içlerinde açıkça gözlenmiştir. Buna karşın X-1şını analizlerinde küçük miktarlarda görülen $\alpha$ fazları optik mikroskop görüntülerinde gözlenmemiştir. Alaşımlarda azalan $\mathrm{Nb}$ konsantrasyonuna karşın artan Ta ile tane sınırlarının daha belirgin olduğu görülmüştür.

Şekil 3 (a-e)'de alaşımların SEM görüntüleri verilmiştir. Şekil 3 (a)'da TiNb alaşımına ait SEM fotoğrafında koyu bölgelerin $\alpha$ çökelti fazının olduğu düşünülmektedir. Aynı şekilde Ta ilavesi ile oluşturulan E1, E2, E3 ve E4 alaşımlarda da koyu bölgelerin $\alpha$ çökelti fazları olduğu tahmin edilmektedir. Bu alaşımlarda $\alpha$ çökelti fazının Ta element ilavesi ile arttığı Şekil 3 (b-e)'de ve EDX sonuçlarında daha net görülmektedir. Özellikle Şekil 3 (d)' deki SEM görüntülerinden, koyu bölgelerin artmasının Ta element ilavesi ile $\alpha$ fazının belirginleşmesinden kaynaklandığı düşünülmektedir. Dikkat çeken Şekil (3 e)'deki SEM görüntüsünün tüm yüzey ve tane sınırlarının birleştiği noktadan (kırmızı ok ile belirtilen kısım) alınan EDX sonuçlarının sırasıyla Ti 72,88 (\% at), Nb 21,43 (\% at), Ta 5,69 (\% at) ve Ti 43,49 (\% at), Nb 4,60 (\% at), Ta 51,91 (\% at) olduğu belirlenmiştir (Şekil 4). Tane sınırlarında Ta elementinin diğer elementlere göre daha fazla oranlarda çıkması, Ta element ilavesinin tane sınırlarını daha belirgin olmasını sağladığının kanıtıdır. $\alpha$ çökelti fazından kaynaklı taneler arası kusurlar ve dislokasyonların tane sınırları boyunca oluştuğu da bilinmelidir [4]. E1, E2 ve E3 alaşımlarında da benzer sonuçlar olduğu bilinmektedir. Ancak, E0, E1, E2 ve E3 alaşımlarında tane sınırlarının SEM görüntüleri belirgin olmayışından EDX analizleri alınamamıştır.

Şekil 5'te alaşımların -40 ile $90{ }^{\circ} \mathrm{C}$ aralığında DSC eğrileri verildi. E0, E1, E2 ve E3 alaşımlarının 1sıtma eğrisinde austenit faz dönüşümünden kaynaklanan $\alpha \rightarrow \beta$ dönüşümü sergilediği gözlenmektedir. Soğutma esnasında herhangi bir dönüşüm gözlenmemiştir. Bu durum üretilen E0, E1, E2 ve E3 alaşımlarının oda sıcaklığındaki ana fazının $\beta$ fazı olduğudur. Bu sonuçlar X-ışınları ve optik mikroskop analizleri ile uyumludur. $\beta \leftrightarrow \alpha$ ters dönüşümlü martensit fazın soğutma esnasında görülmemesinin birkaç sebebinden bahsedilebilir. $M_{s}$ dönüşüm sıcaklığının oda sıcaklığının altında olması DSC analiz sisteminin soğutmadaki bu dönüşüm sıcaklığına düşmemesi, fazı kararlı hale getiren (stabilizatör) elementlerin eklenmesiyle oluşan TiNb-esaslı alaşımlarda ortam koşullarında yarı-kararlı $\beta$ faz yapısını koruma eğilimde olması, martensit dönüşüm entalpisinin düşük olması ve $\beta$ fazından $\alpha^{\prime \prime}$ veya $\alpha$ martensit fazılarına kısmi dönüşümün olması bu sebeplerden bazılarıdır [25]. E4 alaşımının DSC eğrilerindeki 1sıtma ve soğutma esnasında herhangi bir dönüşümün olmaması da bu sebeplerden kaynaklı olabileceği düşünülmektedir. 

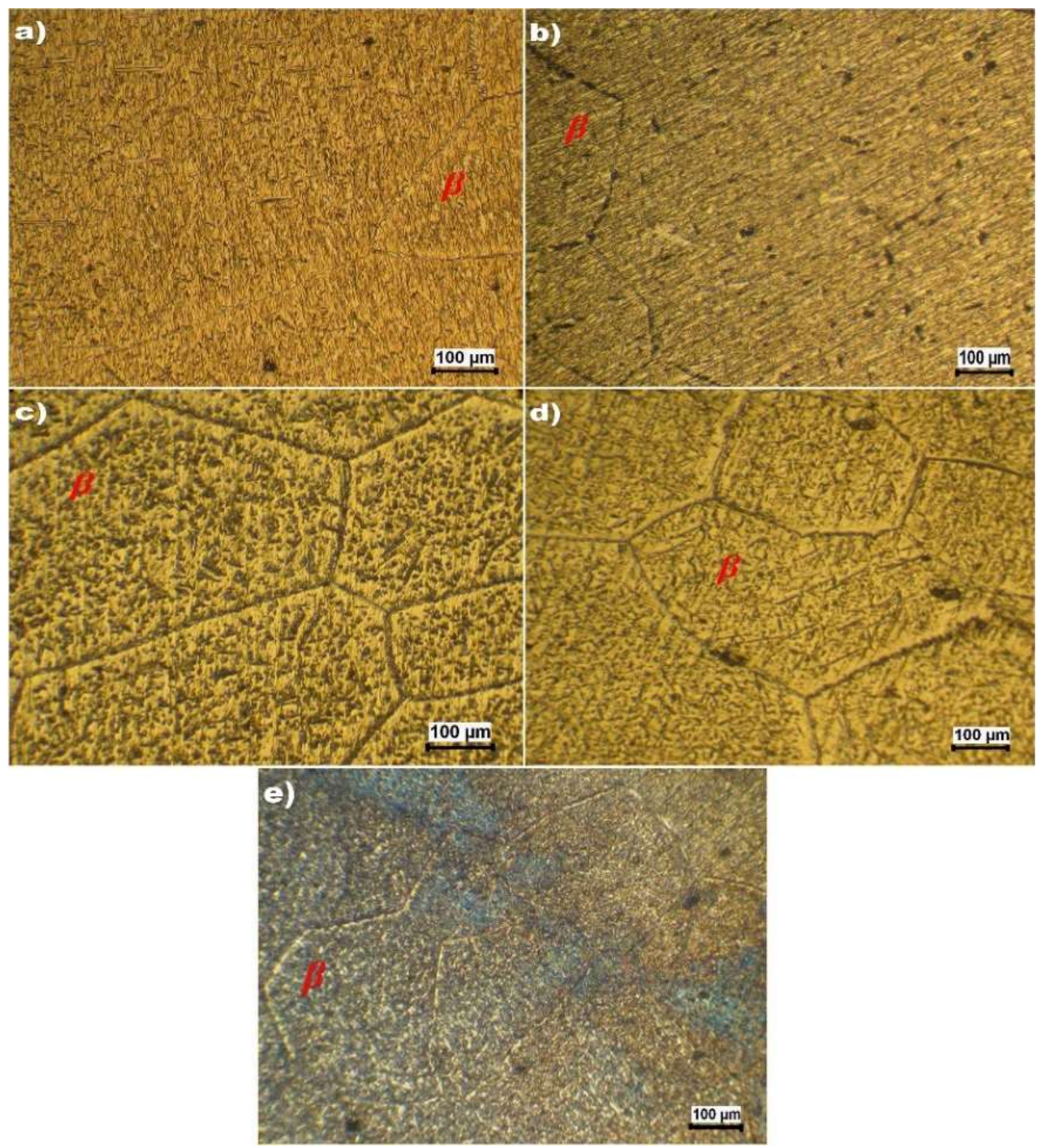

Şekil 2. TiNb ve TiNbTa alaşımlarının optik mikroskop görüntüleri a) E0, b) E1, c) E2, d) E3, e) E4

Yarı-kararlı TiNb esaslı alaşımlarda süper-esneklik ve şekil hafıza özelliklerinin ana $\beta$ fazının geri dönüşümlü termoelastik martensit dönüşüm ile $\alpha^{\prime \prime}$ veya $\alpha$ fazına dönüştürülmesi olayına dayandığı bilinmektedir [22]. Bu dönüşümün zor-zorlanma analizleri ile daha belirgin bir şekilde görüldüğü yapılan çalışmalardan bilinmektedir [13].

TiNb-esaslı alaşımlara Ta elementinin ilavesiyle dönüşüm sıcaklıklarının değiştiği birçok çalışmada belirlenmiştir [14, 25, 26]. Özellikle artan $\mathrm{Nb}$ ve Ta miktarı ile dönüşüm sıcaklığının 30 40K arasında azaldığı bilinmektedir [25]. Yaptığımız çalıșmada azalan $\mathrm{Nb}$ miktarı yerine eklenen Ta elementinin dönüşüm sıcaklıklarını nasıl etkilediği bakımından önemlidir. Şekil 6'da verilen grafikte $\mathrm{A}_{\mathrm{f}}$ dönüşüm sıcaklıkları daha net görülmektedir. $\mathrm{Nb}$ yerine eklenen Ta elementi ile oluşan TiNbTa alaşımının $\mathrm{A}_{\mathrm{f}}$ dönüşüm sıcaklığında da artış ve azalmalar meydana geldiği görülmüştür. $\mathrm{Bu}$ düzensiz değişim yarı-kararlı $\beta$ fazından kaynaklanabileceği düşünülmektedir.

Şekil hafizalı alaşımların dönüşüm sıcaklıklarının $e_{v} / a$, ve $c_{v}$ 'ye bağlı olarak değiştiği Zarinejad ve Liu tarafindan belirlenmiştir [27]. Dönüşüm sıcaklıklarının bağlanma enerjisiyle değiştiği de bilinmektedir [7]. Bu değişimlerin $e_{v} / a$, ve $c_{v}$ ile bağlantılı olması önemlidir. Özellikle düşük değerli olarak adlandırılan $\left(5>e_{v} / a\right)$ şekil hafizalı alaşımların dönüşüm sıcaklıklarının da oda sıcaklığının 
altında olduğu görülmüsstür. Dönüşüm sıcaklıklarının düşük sıcaklıklarda sergilediği düşük elektron konsantrasyonlu $\left(c_{v}, 0,15\right)$ ve düşük valans elektronlu $\left(e_{v} / a<5\right)$ sınırlı sayıda ki TiNb-esaslı alaşımlar vardır [27]. Ürettiğimiz alaşımların $e_{v} / a$, ve $c_{v}$ bakımından düşük değerli olması ve düşük sıcaklıklarda dönüşüm sergilemesi önemlidir. Şekil 6 'da da alaşımların $e_{v} / a$ oranlarının 5 'ten düşük olduğu görülmektedir. Yapılan çalışma ile düşük sıcaklıklarda dönüşüm sergileyen düşük değerli E0, E1, E2, E3 ve E4 alaşımlarının literatüre kazandırılması önemlidir.

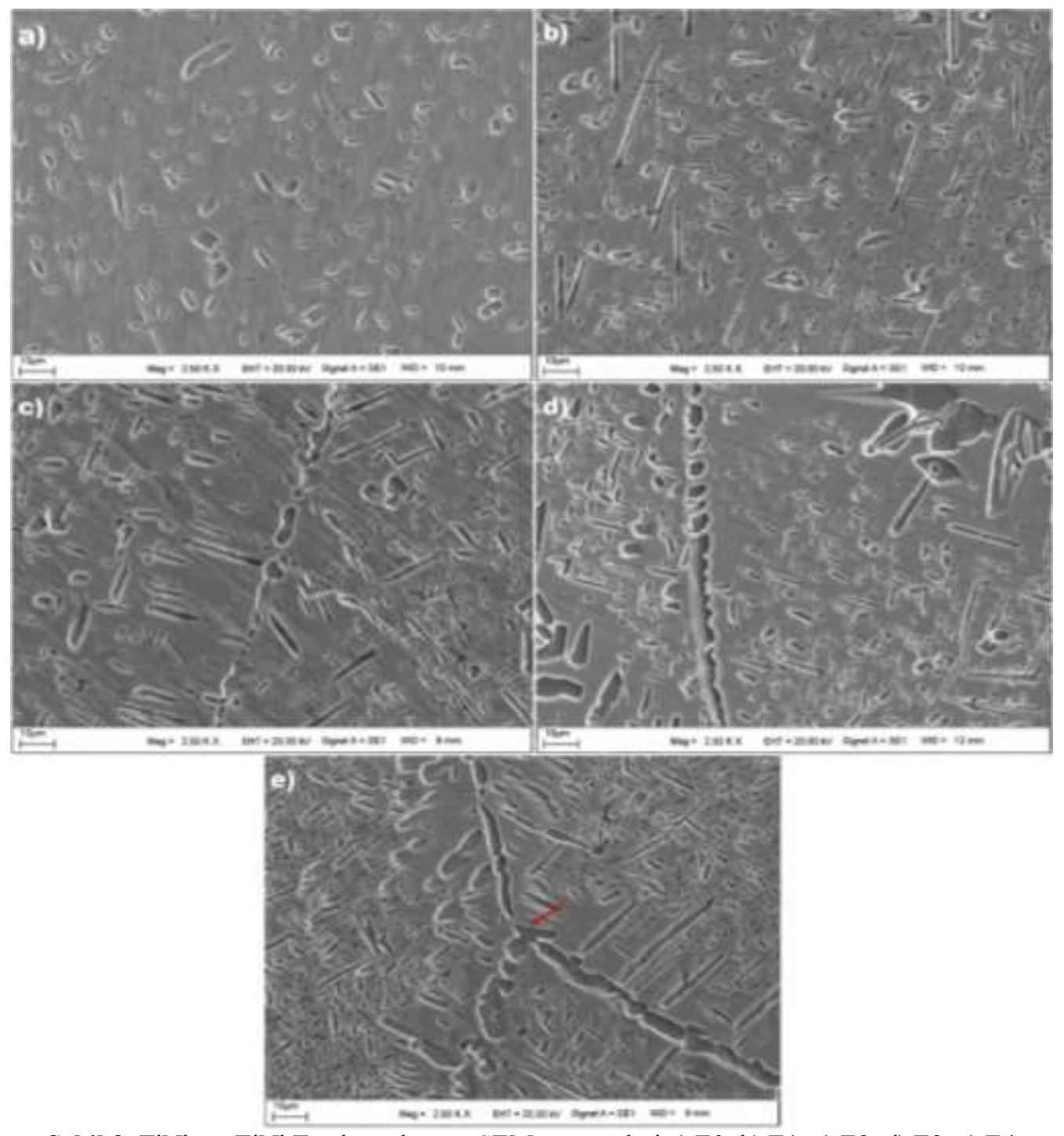

Şekil 3. TiNb ve TiNbTa alaşımlarının SEM görüntüleri a) E0, b) E1, c) E2, d) E3, e) E4
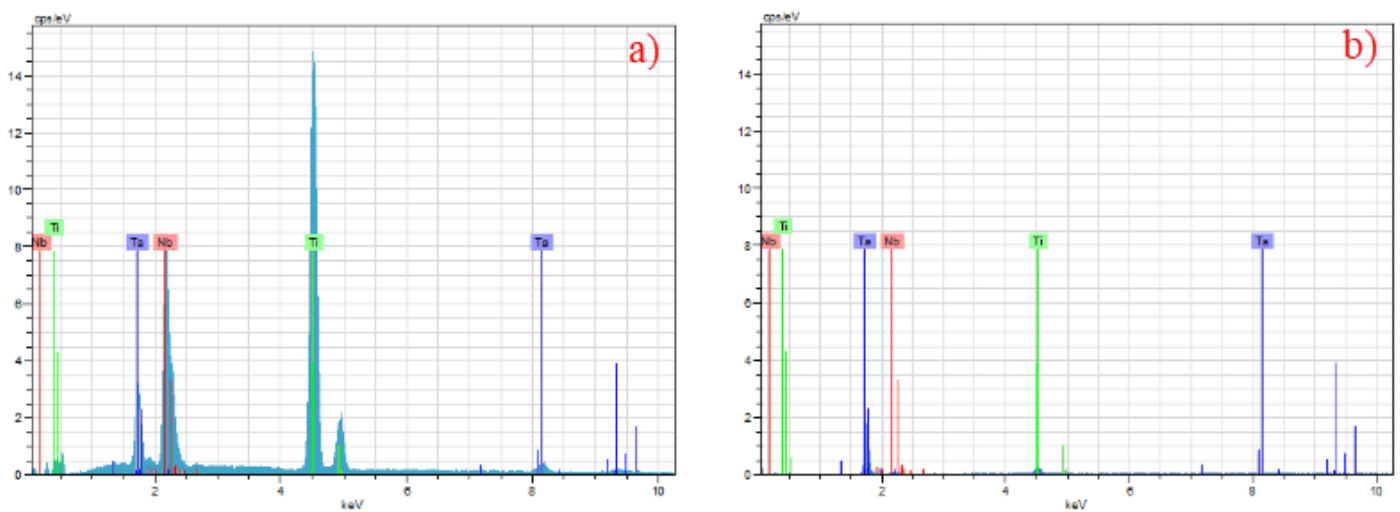

Şekil 4. E4 alaşımın a) tüm yüzey b) belirtilen bölge için EDX sonuçları 


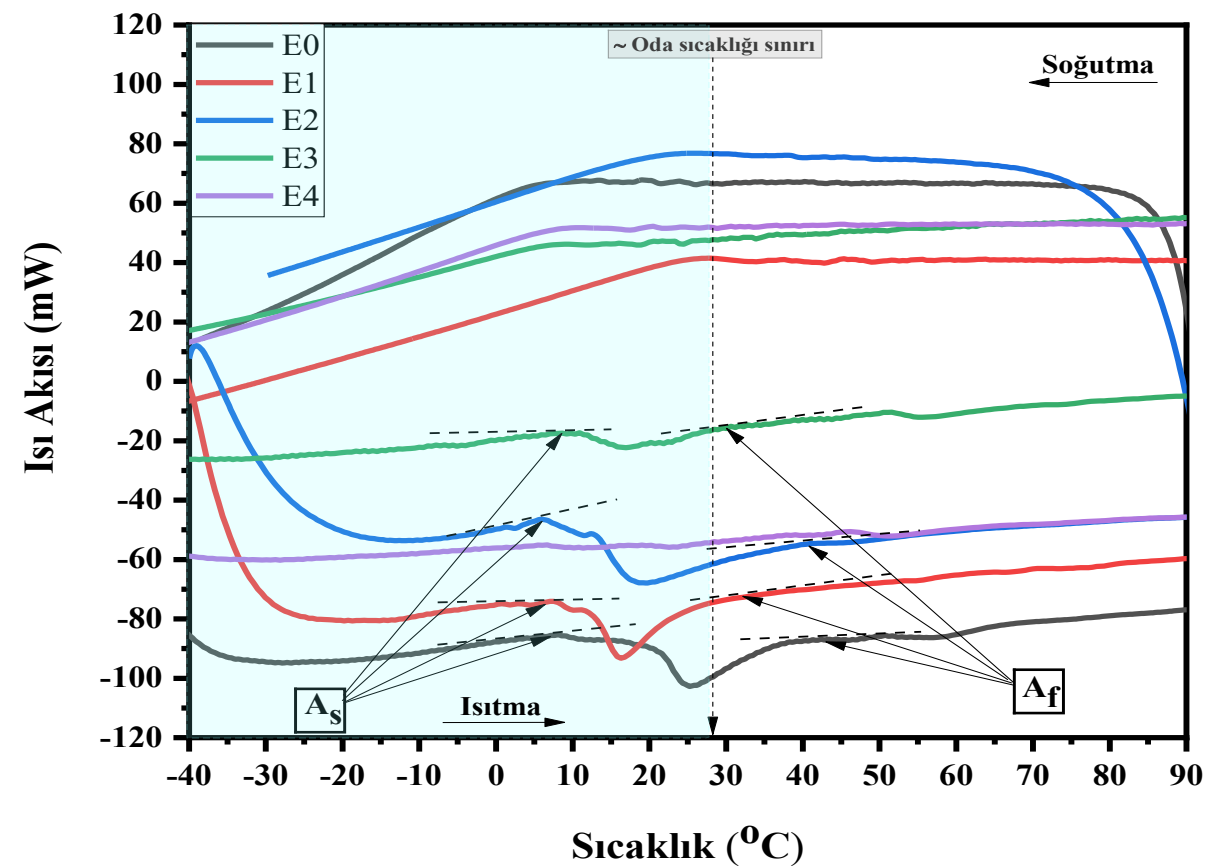

Şekil 5. TiNb ve TiNbTa alaşımlarının DSC sonuçları

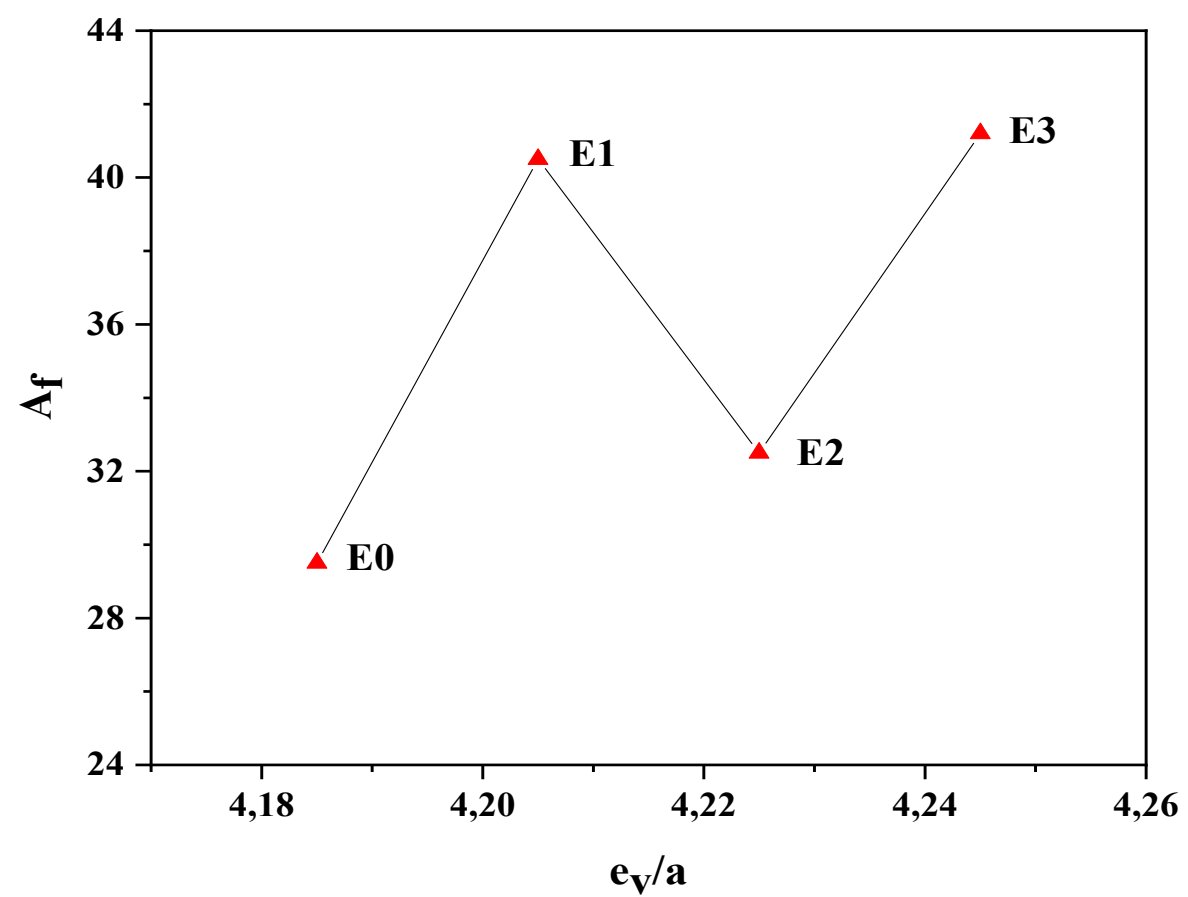

Şekil 6. TiNb ve TiNbTa alaşımlarının $A_{f}$ 'nin $e_{v} / a^{\prime}$ ya göre grafiği

\section{Sonuç ve Öneriler}

Aynı oranlarda $\mathrm{Nb}$ elementinden alınarak yerine eklenen $\mathrm{Ta}$ elementi ile oluşturulan $\mathrm{TiNb}_{(24,5-}$ $\left.{ }_{x}\right) \mathrm{Ta}_{(\mathrm{x}=0,1,2,3,4)}$ (\% at) alaşımlarının $\mathrm{X}$-1şını, optik mikroskop, SEM-EDX ve DSC analizleri alınarak aşağıda verilen sonuçlar elde edilmiştir.

- Oda sıcaklığında alınan X-1şını analizlerinde $\alpha$ fazına karşı1ık gelen piklerin görülmediği ve $\beta$ fazına karşılık gelen piklerin baskın olduğu görülmüştür. Bu fazların yanı sıra küçük miktarlarda $\alpha$ çökelti fazının varlığı ile oksitlenmeden kaynaklanan $\mathrm{TiO}_{2}$ ve $\mathrm{Ta}_{2} \mathrm{O}_{5}$ oksit fazları görülmüştür.

- Optik mikroskop ile kristalografik özellikleri incelenen alaşımlarda $\beta$ martensit fazlarının varlı̆̆ı görülmektedir. Ayrıca alaşımlarda ki tane ve tane sınırları gözlenmiştir. 
- SEM analizleri ile $\alpha$ çökelti fazları olduğu düşünülen yapılar ile tane sınırları daha net bir şekilde görülüp, alaşımlardaki artan Ta elementi ile tane sinırlarında ki Ta miktarının da arttığı EDX analizi ile tespit edilmiştir.

- DSC sonuçları incelendiğinde 1sitma esnasında $\alpha \rightarrow \beta$ dönüşümünün olduğu görülmüştür. Soğutma esnasında herhangi bir dönüşüme rastlanmamıştır. E4 alaşımında ise 1sıtma ve soğutma esnasında herhangi bir dönüşüm gözlenmemiştir.

\section{Teşekkür}

$\mathrm{Bu}$ çalışma Bitlis Eren Üniversitesi Bilimsel Araştırma Projeleri Koordinasyon Birimi (BEBAP) tarafindan 2014.3 ve Fırat Üniversitesi Bilimsel Araştırma Koordinasyonu Birimi (FÜBAP) tarafindan FF.18.30 ve FF.19.06 numaralı projeler kapsamında desteklenmiştir.

\section{Yazarların Katkısı}

Yazarların makaleye olan katkıları eşit orandadır.

\section{Çıkar Çatışması Beyanı}

Yazarlar arasında herhangi bir çıkar çatışması bulunmamaktadır.

\section{Araştırma ve Yayın Etiği Beyanı}

Yapılan çalışmada araştırma ve yayın etiğine uyulmuştur.

\section{Kaynaklar}

[1] Zhou Y.L., Mitsuo N., Toshikazu A., Hisao F., Hiroyuki T. 2005. Corrosion resistance and biocompatibility of Ti-Ta alloys for biomedical applications. Materials Science and Engineering: A, 398 (1-2): 28-36.

[2] Kim H., Hashimoto S., Kim J.I., Hosoda H., Miyazaki S. Effect of Ta addition on shape memory behavior of Ti-22Nb alloy. 2006. Materials Science and Engineering: A, 417 (1-2): 120-128.

[3] Lopes E., Cremasco A., Afonso C., Caram R. 2011. Effects of double aging heat treatment on the microstructure, Vickers hardness and elastic modulus of $\mathrm{Ti}-\mathrm{Nb}$ alloys. Materials characterization, 62 (7): 673-680.

[4] García-Garrido, C., Gonzalez-Gutierrez C., Torrecillas R., Perz-Pozo L., Salvo C., Chicardi. 2019. Manufacturing optimisation of an original nanostructured (beta+ gamma)-TiNbTa material. Journal of Materials Research and Technology, 8 (3): 2573-2585.

[5] Dagdelen F., E Ercan. 2014. The surface oxidation behavior of Ni-45.16\% Ti shape memory alloys at different temperatures. Journal of Thermal Analysis and Calorimetry, 115 (1): 561-565.

[6] Dagdelen F., Kok M., Qader I. 2019. Effects of Ta content on thermodynamic properties and transformation temperatures of shape memory NiTi alloy. Metals and Materials International, 25 (6): 1420-1427.

[7] Kent D., Wang G., Dargusch M. 2013. Effects of phase stability and processing on the mechanical properties of $\mathrm{Ti}-\mathrm{Nb}$ based $\beta \mathrm{Ti}$ alloys. Journal of the Mechanical Behavior of Biomedical Materials, 28: 15-25.

[8] Hussein A., Mohamed A., Ahmad M., Sherif K. 2014. Effect of heat treatment on the microstructure of $\mathrm{Ti}-\mathrm{Nb}-\mathrm{Ta}$ base alloys for biomedical applications. Int. J. Chem. Appl. Biol. Sci, 1: 119.

[9] Mantani Y., Tajima M. 2006. Phase transformation of quenched $\alpha$ "martensite by aging in Ti-Nb alloys. Materials Science and Engineering: A, 438: 315-319.

[10] Dubinskiy S., Prokoshkin S., Brailovski V., Inaekyan K., Korotitskiy A. 2014. In situ X-ray diffraction strain-controlled study of $\mathrm{Ti}-\mathrm{Nb}-\mathrm{Zr}$ and $\mathrm{Ti}-\mathrm{Nb}-\mathrm{Ta}$ shape memory alloys: crystal lattice and transformation features. Materials characterization, 88: 127-142. 
[11] Dubinskiy S., Prokoshkin S.D., Brailovski V., Inaekyan K.E., Korotitskiy A.V., Filonov M.R., Petrzhik M.I. 2011. Structure formation during thermomechanical processing of Ti-Nb-(Zr, Ta) alloys and the manifestation of the shape-memory effect. The physics of metals and metallography, 112 (5): 503-516.

[12] Inaekyan K., Brailovski V., Prokoshkin S., Pushin V., Dubinskiy S., Sheremetyev V. 2015. Comparative study of structure formation and mechanical behavior of age-hardened $\mathrm{Ti}-\mathrm{Nb}-\mathrm{Zr}$ and $\mathrm{Ti}-\mathrm{Nb}-\mathrm{Ta}$ shape memory alloys. Materials Characterization, 103: 65-74.

[13] Dubinskiy S., Brailovski V., Pokoshkin A., Pushin V., Inaekyan K., Sheremetyev V., Petrzhik M., Filonov M. 2013. Structure and properties of Ti-19.7 Nb-5.8 Ta shape memory alloy subjected to thermomechanical processing including aging. Journal of materials engineering and performance, 22 (9): 2656-2664.

[14] Brailovski V., Prokoshkin S., Gauthier M., Inaekyan K., Dubinskiy S., Petrzhik M., Filonov. 2011. Bulk and porous metastable beta $\mathrm{Ti}-\mathrm{Nb}-\mathrm{Zr}$ (Ta) alloys for biomedical applications. Materials Science and Engineering: C, 31 (3): 643-657.

[15] Takahashi E., Sakurai T., Watanabe S., Masahashi N., Hanada S. 2002. Effect of heat treatment and $\mathrm{Sn}$ content on superelasticity in biocompatible TiNbSn alloys. Materials Transactions, 43 (12): 2978-2983.

[16] Fukui Y., Inamura T., Hosoda H., Wakashima K., Miyazaki S. 2004. Mechanical properties of a Ti-Nb-Al shape memory alloy. Materials Transactions, 45 (4): 1077-1082.

[17] Kim J.I., Kim H.Y., Hosoda H., Miyazaki S. 2005. Shape memory behavior of Ti-22Nb-(0.52.0) $\mathrm{O}$ (at\%) biomedical alloys. Materials transactions, 46 (4): 852-857.

[18] Tahara M., Kim H.Y., Hosoda H., Miyazaki S. 2009. Shape memory effect and cyclic deformation behavior of Ti-Nb-N alloys. Functional Materials Letters, 2 (02): 79-82.

[19] Al-Zain Y., Kim H.Y., Hosoda H., Nam T.H., Miyazaki S. 2010. Shape memory properties of Ti-Nb-Mo biomedical alloys. Acta Materialia, 58 (12): 4212-4223.

[20] Kim H.Y., Oshika N., Kim J. Inamura T., Hosoda H., Miyazaki S. 2007. Martensitic transformation and superelasticity of Ti-Nb-Pt alloys. Materials transactions, 48 (3): 400-406.

[21] Ping, D., Mitarai Y., Yin F. 2005. Microstructure and shape memory behavior of a Ti-30Nb-3Pd alloy. Scripta materialia, 52 (12): 1287-1291.

[22] Kim H., Sasaki T., Okutsu K., Kim J., Inamura T., Hosoda H., Miyazaki S. 2006. Texture and shape memory behavior of Ti-22Nb-6Ta alloy. Acta Materialia, 54 (2): 423-433.

[23] Bertrand E., Gloriant T., Gordin D.M., Vasiles u E., Drob P., Vasilescu C., Drob S.I. 2010. Synthesis and characterisation of a new superelastic Ti-25Ta-25Nb biomedical alloy. Journal of the mechanical behavior of biomedical materials, 3 (8): 559-564.

[24] Hussein A.H., Gepreel H., Gouda M.K., Hefnawy A.M., Kandil S.H., 2016. Biocompatibility of new Ti-Nb-Ta base alloys. Materials Science and Engineering: C, 61: 574-578.

[25] Qu, W.-T., Gong H., Wang J., Nie Y-S., Li Y. 2019. Martensitic transformation, shape memory effect and superelasticity of Ti-xZr-(30-x) Nb-4Ta alloys. Rare Metals, 38 (10): 965-970.

[26] Kim H.Y., Miyazaki S. 2016. Several issues in the development of Ti-Nb-based shape memory alloys. Shape Memory and Superelasticity, 2 (4): 380-390.

[27] Zarinejad M., Liu Y. 2010. Dependence of transformation temperatures of shape memory alloys on the number and concentration of valence electrons, Nova Science Publishers, Inc., New York, 339. 